\title{
COMPUTATIONAL ELECTROMAGNETICS AND INDUSTRY
}

\begin{abstract}
Special concerns relevant in the current climate of over-specialisation and a perceived weakening in taking proper notice of the requirements of industry are examined. The discussion examines the nature of CEM and notes the main topics researched in the last 25 years using the International Compumag Conference as an exemplar. This is followed by an assessment of industrial needs and the means by which a relationship between designers and method developers could be strengthened. The status and management of CEM bench marking activities are highlighted with a special reference to the TEAM (Testing of Electromagnetic Analysis Methods) exercise since its introduction in 1995. Finally, we provide some comments on how the community might be best organised to meet future challenges.
\end{abstract}

\section{Authors}

C W Trowbridge

Vector Fields Ltd

D’Arcy's Field

Ford Lane

Frilford, OXON, OX13 5NS

E-mail: bill@trowbridge.org.uk

Web: www.trowbridge.org.uk

\section{J K Sykulski}

Department of Electronics and Computer Science

University of Southampton

Southampton SO17 1BJ

E-mail: J.K.Sykulski@soton.ac.uk

http://www.epe.ecs.soton.ac.uk/

http://www.ecs.soton.ac.uk/info/people/jks 


\section{COMPUTATIONAL ELECTROMAGNETICS AND INDUSTRY}

\author{
C W Trowbridge and J K Sykulski
}

Vector Fields Ltd, UK

University of Southampton, UK

\section{INTRODUCTION}

This paper examines some special concerns that appear to us to be relevant in the current climate of overspecialisation and perhaps a perceived weakening in taking proper notice of the requirements of industry. We begin by discussing the nature of CEM and noting the main topics researched in the last 25 years. This is followed by an assessment of industrial needs and the means by which a relationship between designers and method developers could be strengthened. Finally, we provide some remarks on how the community might be best organised to meet future challenges.

\section{RETROSPECTIVE}

The research activity usually known as Computational Electromagnetics (CEM) has evolved alongside the modern developments in the digital computing hardware, though its origins can be traced back to earlier times when mechanical computing engines, analogue electrical devices and just pen and paper were used to solve the field equations. The primary motivation - quite properly - has been to serve the requirement of engineering in the production of useful devices of benefit to society as a whole but often for defence purposes. By and large governments (through research agencies) and industry have been the providers of funds for this research - a fact often overlooked by those whose motivation is to develop tools for their own sake. However, we must not deny that CEM is also a scientific discipline that is capable of gathering its own momentum and producing new and far reaching ideas. As an example, consider the development of the Finite Element Method (FEM) which grew out of the structural mechanics community serving the aircraft industry in war time. Its development, though based on classical principles, was driven by the needs of the industries involved and was only later studied by theoreticians who made the connections with mainstream mathematics. Thus we had an extremely successful and far reaching empirical numerical technique innovated and developed by engineers and only later made 'mathematically' respectable which lead to deeper understanding and new directions achieved.

\section{CEM TOPICS}

CEM is both a special case and part of the broader subject of computational mechanics. The speciality arises in many obvious ways, e.g. free space is, in general, an unbounded magnetic 'material' and any modelling, often involving complex structures, has to take this into account. There is also the vast range of physical dimensions encountered in CEM; thus critical feature sizes can vary over many orders of magnitude as for example in the modelling of permanent magnetic materials and electron beam devices. The speciality also arises more subtly as Maxwell's equations in general have fundamental properties that are different say from the Navier Stokes equations that govern fluid mechanics. The nature of the main topics studied is shown in Table 1 by sampling the 2000 or so papers published resulting from the Compumag Conference for this and other information on the status of CEM see Trowbridge and Sykulski (1).

TABLE 1 - Compumag Conference Topics Percentage in each topic

\begin{tabular}{llllllllllllll}
\hline Conference & 1 & 2 & 3 & 4 & 5 & 6 & 7 & 8 & 9 & 10 & 11 & 12 & $13^{1}$ \\
Year & 76 & 78 & 81 & 83 & 85 & 87 & 89 & 91 & 93 & 95 & 97 & 99 & 01 \\
\hline Static & 34 & 32 & 22 & 18 & 14 & 9 & 9 & 9 & 12 & 9 & 8 & 8 & 5 \\
Quasi Static & 48 & 37 & 34 & 31 & 31 & 24 & 15 & 17 & 15 & 11 & 12 & 10 & 9 \\
Wave Prop & & & & & & & & & 13 & 11 & 9 & 8 & 11 \\
Optimisation. & & 3 & 3 & & & 4 & 5 & 10 & 7 & 14 & 15 & 14 & 12 \\
Material & 9 & 3 & 9 & 7 & 6 & 4 & 3 & 3 & 5 & 8 & 5 & 7 & 9 \\
Coupled & 0 & 0 & 1 & 3 & 2 & 9 & 7 & 8 & 16 & 11 & 12 & 14 & 11 \\
NMeths & 0 & 5 & 8 & 11 & 13 & 9 & 20 & 20 & 9 & 10 & 14 & 14 & 11 \\
Software & 3 & 8 & 4 & 9 & 8 & 14 & 12 & 6 & 8 & 5 & 5 & 4 & 3 \\
Applications & 6 & 12 & 18 & 20 & 25 & 26 & 29 & 27 & 16 & 15 & 17 & 18 & 22 \\
EMC & & & & & & & & & & 7 & 3 & 3 & 4 \\
Education & & & & & & & & & & & & 1 & 2
\end{tabular}

\begin{tabular}{llllllllllllll} 
Papers Pub. & 65 & 60 & 76 & 98 & 106 & 143 & 177 & 193 & 225 & 266 & 308 & 279 & 249 \\
\hline
\end{tabular}

It should be noted that Compumag began as a low frequency meeting and it is only since 1993 that high frequency topics have been included. It can also be seen that industrially important subjects like optimisation, coupled phenomena and material modelling are of equal popularity to subjects concerned covering fundamentals. It is also apparent that 'applications and devices' is the largest area $(\sim 20 \%)$ but routine applications of methods were not permitted. EMC is now covered and is expected to increase to match the demand created by industry in the telecommunications sector. The organisers are also now encouraging papers on Education methods and techniques for CA Learning.

\section{INDUSTRIAL NEEDS}

There are two main areas to consider: first, the R \& D of new and improved devices for which advanced CEM software is needed and secondly, the creation of a

\footnotetext{
${ }^{1}$ Estimates only
} 
product which almost always goes beyond the narrow discipline of electromagnetics and requires numerical solutions for multi-physics coupled phenomena. Indeed the limiting factors of cost and time to market often depend on these other disciplines. Hence study of coupled problem solution is paramount It has been heartening to note from Table 1 that much attention has been given to this and to overall embracing subject of optimisation. Having said this, however, there is another crucial topic that has a direct bearing on the willingness of Industrial firms to accept our developments and that is testing and benchmarking.

\section{VALIDATION OF METHODS FOR INDUSTRY}

As an example of what has been achieved we discuss the TEAM workshops (http://ics.ec-lyon.fr/team.html) which have now been regularly held for the last fifteen years, see Turner (1), and have been widely appreciated by the technical community.

Successes. The original purpose of the workshops, as the acronym suggests, is 'Testing Electromagnetic Analysis Methods' and initially methods for Eddy Current analysis were given priority, although later both static and high frequency problems were admitted to the canon. The main achievements are:

- Standard formulations, using for the most part variations on the finite element method, have been studied and reported at workshops with subsequent critical comments written by 'problem' coordinators and made available in the literature.

- This has in turn stimulated a more critical approach to problem solving.

- Furthermore, it has lead to exchanges of information and knowledge among method developers.

Limitations. A number of limitations can be observed which mostly stem from the historical role played by academia and the research laboratories in providing new developments.

- The involvement of industry has not been sufficient to guarantee a significant influence by industrial engineers who are researching and designing electromagnetic devices and on the whole the direct influence of industry has been slight.

- Also the CEM software industry, though a keen observer, has not been sufficiently involved.

- The organization, though very flexible and in the spirit of academic freedom, does not allow planning to match future needs.

\section{What can be done?}

- Problems need to be more industrially relevant. Representatives from industry could be invited to submit critical problems.

- Problem classes can be introduced based on industrial needs, i.e., machines, transformers, actuators, space charge devices, superconducting magnets, electrostatics, magnetic materials, etc.

- More emphasis on numerical error estimation and investigations into convergence with respect to discretisation.

- More emphasis on experimental accuracy.

- Reporting sessions within the CEM conferences that involve developers, industrial users and software vendors.

\section{FUTURE ORGANISATION}

Apart from making CEM more industrially relevant the community itself needs to rationalise its procedures. One of the problems is the over production of papers we have seen in recent years which stems from the need for academics to publish their work in order to score 'brownie points'. Part of the issue here is that there are too many conferences scheduled which often encourages researchers to repeat earlier work or to present material that is only work in progress. This in itself is fine in a workshop but not for papers that are aimed at transactions. The refereeing burden has also become intolerable.

An attempt at international coordination is urgently needed. The main societies and conference organisers need to come together and plan for the future to avoid close proximity to meetings of similar scope and establish standards in benchmarking. Of particular importance is the involvement of industry who are ultimately the customers for all new developments in methods, techniques and tools. There is a role for the new Professional Networks of IEE, in particular PN Electromagnetics, to provide a framework for international collaboration between academic, research and industrial institutions. This process has already started but significant progress is needed to achieve some of the goals defined above.

\section{REFERENCES}

1. Trowbridge, C. W. and Sykulski, J. K., 1998, COMPEL, 17, 33-46

2. Turner, L., 1988, COMPEL, 7, 3-9 